\title{
The Impact of First-Line Anti-Tubercular Drugs' Pharmacokinetics on Treatment Outcome: A Systematic Review
}

This article was published in the following Dove Press journal: Clinical Pharmacology: Advances and Applications

\author{
Tesemma Sileshi ${ }^{1,2}$ \\ Esayas Tadesse (iD) \\ Eyasu Makonnen ${ }^{2}$ \\ Eleni Aklillu (iD) ${ }^{3}$ \\ 'Ambo University, Department of \\ Pharmacy, Ambo, Ethiopia; ${ }^{2}$ Addis Ababa \\ University, College of Health Sciences, \\ Addis Ababa, Ethiopia; ${ }^{3}$ Karolinska \\ Institutet, Department of Laboratory \\ Medicine, Stockholm, Sweden
}

Background: Tuberculosis remains the major public health problem besides tremendous efforts to combat it. Most tuberculosis patients are treated with a standard dose of first-line anti-TB drugs. The cure rate, however, varies from patient to patient. Various factors have been related to anti-TB treatment failure. In recent years, studies associating lower plasma concentrations of anti-TB drugs with poor treatment outcomes are emerging although the results are inconclusive.

Objective: Investigate the impact of first-line anti-tubercular drugs pharmacokinetics on treatment outcome.

Methods: A systematic search of Pubmed, EMBASE, Web of Science, and the Cochrane Library for articles published in the English language between January 2010 to June 2020 was conducted to identify eligible studies describing associations of first-line anti-tubercular drug pharmacokinetics with treatment outcomes. The primary outcomes considered were pharmacokinetics parameter results and its association with treatment outcome.

Results: The search identified 1754 articles of which twelve articles; ten prospective observational studies and two controlled clinical trials fulfilled the eligibility criteria. The majority of the studies showed target concentrations for the first-line anti-tubercular drugs below the current standard range. Among the twelve studies, eleven studies assessed rifampicin pharmacokinetics of which eight reported association of drug concentration and treatment outcomes. Similarly, four out of eight and three out of seven reported drug concentration and treatment outcome association for isoniazid and pyrazinamide, respectively. Despite the low plasma concentration, a favorable treatment outcome was achieved for the bulk of the patients. Irrespective of the inconsistency, an increase in exposure to rifampicin improved the outcome, and lower rifampicin, isoniazid, and pyrazinamide concentration are associated with poor outcome. No data are available for ethambutol associating its pharmacokinetics with treatment outcomes.

Conclusion: The pharmacokinetics of first-line antitubercular drugs can influence treatment outcomes. Further controlled clinical studies are, however, required to establish these relationships.

Keywords: tuberculosis, pharmacokinetics, treatment outcomes, anti-TB drugs

\section{Introduction}

Tuberculosis (TB), an infectious disease caused by Mycobacterium Tuberculosis, stays the main health problem globally. TB is one of the top 10 causes of death and the leading cause of death from infectious diseases worldwide. According to the world health organization (WHO) 2019 tuberculosis report, TB caused an estimated
Correspondence: Tesemma Sileshi Ambo University, P.O Box 19 Ambo University, Ambo, Ethiopia

Tel +25I 911550975

Email tesemmasileshi@gmail.com
Clinical Pharmacology: Advances and Applications 2021:13 I-12

(c) (i) (ङ) 202I sileshi et al. This work is published and licensed by Dove Medical Press Limited. The full terms of this license are available at https://www.dovepress.com/terms. (c) ${ }_{\mathrm{BY}} \mathrm{NC}_{\mathrm{Nh}}$ and incorporate the Creative Commons Attribution - Non Commercial (unported, v3.0) License (http:///creativecommons.org/licenses/by-nc/3.0/). By accessing the work you hereby accept the Terms. Non-commercial uses of the work are permitted without any further permission from Dove Medical Press Limited, provided the work is properly attributed. For permission for commercial use of this work, please see paragraphs 4.2 and 5 of our Terms (https://www.dovepress.com/terms.php). 
1.2 million deaths among HIV-negative people and 251 000 deaths among HIV positive people in 2018. ${ }^{1}$ The aspiring strategy of WHO to END TB aims to reduce TB incidence and mortality in 2035 by $90 \%$, and $95 \%$, respectively compared to the 2015 cases. $^{2}$ The first line anti-TB drugs which include rifampicin (RMP), isoniazid (INH), pyrazinamide (PZA), and ethambutol (EMB) have a cure rate of up to $95 \%$ in early clinical trials, ${ }^{3}$ but the success rates drop as low as $65 \%$ in some areas. ${ }^{4}$ Drug resistant TB poses a key threat to control TB globally with the firstline drugs. For example, the incidence of multi-drug resistance (MDR-TB) and extensive multi-drug resistance (XDR-TB) is increasing over time, for instance, 484,000 cases of MDR-TB cases were reported in 2018 which could decrease the success achieved. ${ }^{2}$

Many factors might be associated to treatment failure. Health factors such as HIV infection, diabetes mellitus, low body weight, cavitation on chest x-ray, high bacterial burden, drug resistance, positive culture after two months of treatment; and sociodemographic factors like drug abuse, alcoholism, smoking, and poor treatment adherence were reported in several studies. ${ }^{5-10}$ Data from mice, ${ }^{11}$ and hollow fiber system (HFS) models, ${ }^{12}$ emphasized pharmacokinetic studies to predict tuberculosis treatment outcome. Furthermore, WHO recognized pharmacokinetics (PK) and pharmacodynamics (PD) studies to play a key role to establish the most appropriate dose of anti-TB medications. ${ }^{13}$

PK describes the time course of a drug concentration in different body compartments, such as blood, plasma, brain, lungs, and other tissue. It deals with what the body does to the drug; absorption, distribution, metabolism, and excretion. ${ }^{14}$ Poor compliance to treatment has been considered as the major cause for treatment failure in tuberculosis treatment historically. ${ }^{15}$ However, in recent years, several studies associated low serum concentrations of anti-TB drugs with poor treatment outcomes. The reference range for various first-line anti-TB drugs with therapeutic cut-offs is given in Table $1 .{ }^{16} \mathrm{PK}$ parameters especially the total exposure to anti-TB drugs (the area under the plasma concentration vs time curve (AUC0-24) and/or the peak plasma concentration (Cmax) appear to be relevant for anti-TB drugs. ${ }^{17}$

Systematic reviews and meta-analyses describing relations of PK and treatment outcome have been published previously. ${ }^{18-22}$ However, the objectives and conclusions of these reviews or meta-analyses were not consistent (Table S1). For example, Pasipanodya et al reviewed the
Table I Basic Pharmacokinetics of First-Line Anti-Tubercular Drugs $^{16}$

\begin{tabular}{|l|l|l|l|l|}
\hline $\begin{array}{l}\text { Drug } \\
\text { Name }\end{array}$ & Dose & $\begin{array}{l}\text { Serum } \\
\text { Cmax } \\
(\mu \mathrm{gg} / \mathrm{mL})\end{array}$ & $\begin{array}{l}\text { Tmax } \\
(\mathbf{h r})\end{array}$ & $\begin{array}{l}\text { Serum T1/2 } \\
(\mathbf{h r})\end{array}$ \\
\hline Rifampicin & $600 \mathrm{mg}$ & $8-24$ & 2 & $2-3$ \\
\hline Isoniazid & $300 \mathrm{mg}$ & $3-6$ & $0.75-2$ & $\begin{array}{l}1.5 \text { fast } \\
4 \text { slow }\end{array}$ \\
\hline Pyrazinamide & $25-35 \mathrm{mg} / \mathrm{kg}$ & $20-60$ & $\mathrm{I}-2$ & 9 \\
\hline Ethambutol & $25 \mathrm{mg} / \mathrm{kg}$ & $2-6$ & $2-3$ & $\begin{array}{l}\text { Biphasic: } \\
2-4, \text { then } \\
\text { I2-14 }\end{array}$ \\
\hline
\end{tabular}

shreds of evidence on the association of isoniazid pharmacokinetic variability with either microbiological failure or acquired drug resistance and concluded pharmacokinetic variability of isoniazid was significantly associated with failure of therapy and acquired drug resistance in patients. ${ }^{18}$ However, reviews focused on the association of drug concentration and treatment outcomes have contradicting conclusions. Perumal et al have shown that low PZA concentration probably increased the risk of poor outcomes; low RMP concentration might slightly increase the risk of poor outcomes; whereas low concentrations of INH and EMB had no clear effect on the treatment outcome. $^{22}$ On another hand, Sekaggya-Wiltshire et al and Wilby et al failed to reach on a conclusion that plasma concentration of first-line anti-tubercular drugs affects treatment outcome. ${ }^{19,21}$

In addition to variation in the conclusion, the majority of the previously published reviews included all types of studies ranging from controlled clinical trials to case reports leading to a varying degree of evidence. ${ }^{23}$ This systematic review was, therefore, designed to evaluate the recent evidence on the effects of pharmacokinetics in particular plasma concentration on tuberculosis treatment outcome by reviewing only prospective cohort studies and randomized clinical trials that have a better level of evidence.

\section{Methods}

\section{Literature Search Strategy}

We conducted the review according to the Preferred Reporting Items for Systematic Reviews (Table S2) and Meta-Analyses (PRISMA) statement. The protocol was registered at PROSPERO (Registration number CRD42019138544. ${ }^{24}$ 
We identified studies among tuberculosis patients in which all or any of the first-line anti-tubercular drug pharmacokinetic data or drug concentration and tuberculosis treatment outcomes were reported. A systematic search of Pubmed, EMBASE, and Web of Science for articles published in the English language over the last ten years (January 1, 2010- June 8, 2020) was done. We applied the search strategy including the next terms: "antitubercular agents" OR antituberculosis OR antimycobacterial, OR Isoniazid OR Pyrazinamide OR Rifampicin OR Rifampin OR Ethambutol AND "pharmacokinetics" or "concentration" AND "treatment outcomes" OR "sputum conversion" OR "culture conversion". We hand search reference lists from relevant studies, to identify further eligible articles not found by the systematic search. The search included only adult human studies.

\section{Eligibility Criteria}

The following inclusion criteria were used to select studies: patients (15 years and above) and treated with firstline anti-tubercular drugs (INH, RMP, PZA, and EMB) according to WHO treatment guidelines and at least one of whose PK data described. Only prospective cohort studies and controlled clinical trials were included. However, studies reporting pharmacokinetics effect on treatment outcome in children were excluded. Besides, population modeling, review article, retrospective studies, case-control, and case series studies were excluded. There is no limitation based on gender and other sociodemographic characteristics of study participants.

\section{Data Quality Assessment}

The included study quality was assessed using appropriate tools. Blended Cochrane's Risk of Bias assessment of Randomized Controlled Trials for controlled clinical trial studies with the Newcastle-Ottawa Quality Assessment Scale for cohort studies was used to assess the quality of the included studies. Quality assessment of the studies was done by one author (TS) using the prepared checklist (Table S3).

\section{Data Extraction}

A pre-designed data extraction form was used to review relevant studies (Table S4). Two authors (TS and ET) independently extracted data. Included articles were read and screened for eligibility criteria. From the studies included in the review, data were collected on study design, participant characteristics, pharmacokinetic parameters (Cmax, AUC or Cmax/MIC, AUC/MIC), treatment outcomes (cure, relapse, failed, culture conversion, smear conversion), the correlation between PK parameters, and treatment outcomes. The pharmacokinetics parameter results and its' association with treatment outcome were the primary outcomes considered strictly during data extraction for each study included. Disagreements between the two reviewers during data extraction were resolved through discussion. Similarly, if any ambiguity on the study methods or results was encountered the two reviewers discussed the issue together and resolved the ambiguity. No synthesis of data was done and contact of authors was not found to be relevant during the review for original data.

\section{Results Study Characteristics}

As shown in Figure 1, a total of 1754 articles was identified. Of which, 47 duplicates and 1665 articles evaluated by their titles and abstracts were excluded. The remaining 42 studies were further evaluated through the full reading of their texts. 30 studies were excluded further because they are either review article, population pharmacokinetic modeling, retrospective studies, not having treatment outcome reported, or luck of pharmacokinetics data either AUC, Cmax, or both. The remaining 12 studies were selected for the final qualitative analysis. The geographic location of the included studies was; six from Africa, ${ }^{25-30}$ one from Europe, ${ }^{31}$ two from Latin America, ${ }^{32,33}$ and the remaining three from Asia. ${ }^{34-36}$ The majority of the studies were observational prospective in design. Only two of the studies included in this review were randomized clinical trials as shown in Table 2. ${ }^{30,32}$ The median (mean) age of study participants ranges from 25 to 42 . In all studies, some participants had comorbid conditions; either HIV or diabetes mellitus. ${ }^{29,33-36}$ The PRISMA Flow diagram is shown in Figure 1.

\section{Quality of Included Studies}

All studies were assessed for the following parameters; 1. Representativeness of the selected cohorts (treatment of tuberculosis was with first-line anti-tubercular drugs) 2 . The outcome of interest was not presented at the start of the study (no reported drug resistance at the beginning of treatment) 3. Compatibility of study participant 4. Assessment of outcome (treatment outcome listed above) 5. Adequacy of the duration of follow-up (at least for two 


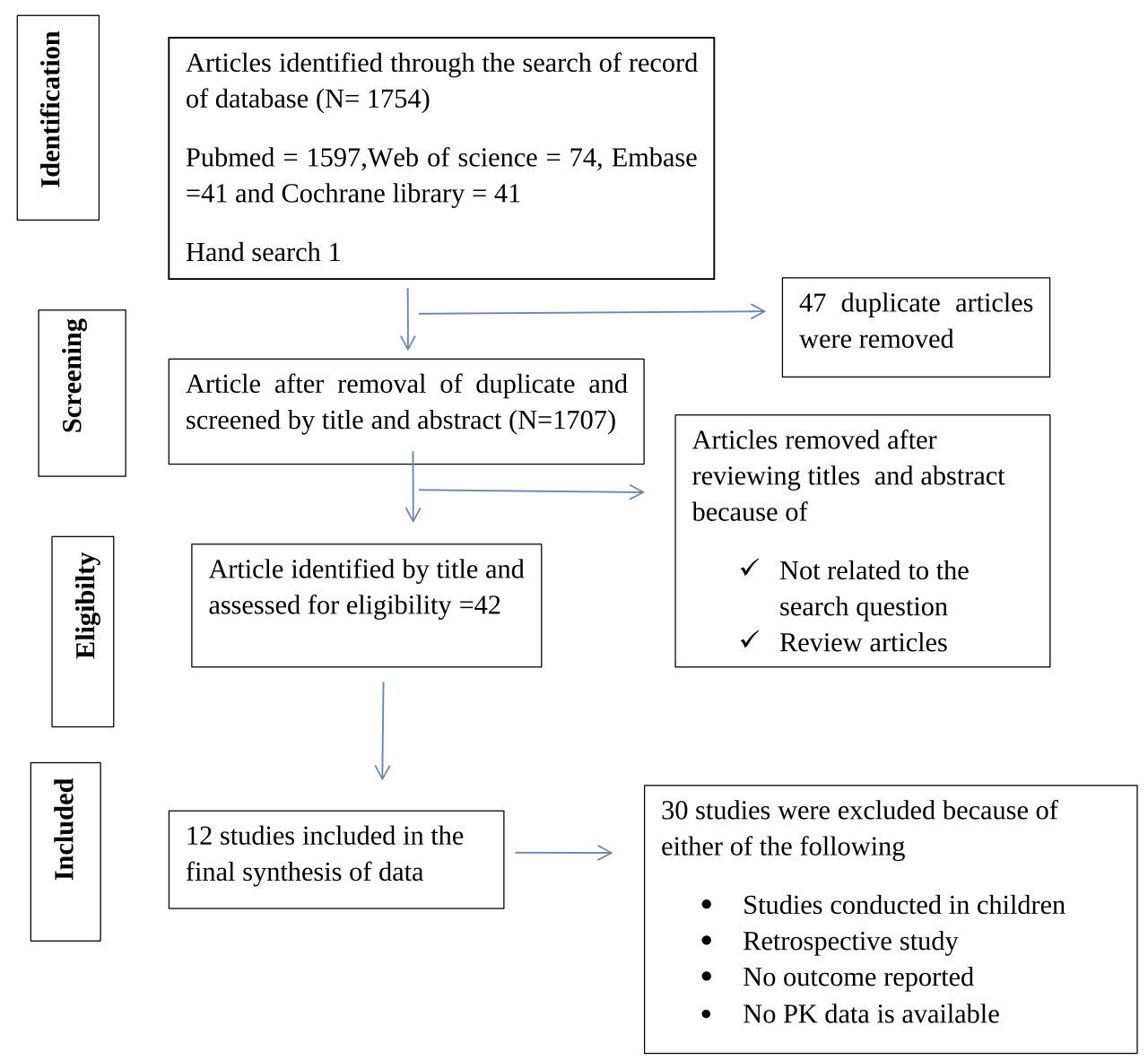

Figure I PRISMA flow diagram showing the literature search for studies which described drug pharmacokinetics of first line tuberculosis drugs and treatment outcomes. Notes: PRISMA figure adapted from Liberati A, Altman D, Tetzlaff J, et al. The PRISMA statement for reporting systematic reviews and meta-analyses of studies that evaluate health care interventions: explanation and elaboration. Journal of Clinical Epidemiology. 2009;62(I0). Creative Commons.

Abbreviations: PK, pharmacokinetics; PRISMA, Preferred Reporting Items for Systematic Reviews and Meta-Analyses.

months) and for controlled randomized clinical trials, a randomization process was considered. Ten of the twelve studies were observational prospective studies. As shown in Table 2 all prospective observational studies have a low risk of bias. Similarly, in the remaining two randomized controlled clinical trials, although the proportion of patients with low PK and poor treatment outcomes was not indicated, they had a low risk of bias.

\section{Pharmacokinetic Data and Treatment Outcome}

Among the twelve studies evaluating PK parameters with treatment outcome, four assessed RMP only, ${ }^{26,27,30,32}$ one INH only, ${ }^{33}$ five three drugs (RMP, INH, and PZA) $)^{25,29,34-36}$ and two all drugs (RMP, INH, PZA, EMB) ${ }^{28,31}$ All studies reported clinical outcomes and their association with some kind of pharmacokinetics parameters. However, the proportion of patients with a low level of drug concentration was not reported in four studies. ${ }^{27,30,32,36}$ Eight studies reported the proportion of study participants who had low plasma concentration. Strikingly, in one study, $100 \%$ of participants have low plasma Cmax measured at 2.5 -hour post-dose. ${ }^{26} \mathrm{In}$ the majority of the studies that reported plasma levels of the drug, a large percentage of participants had a lower plasma concentration of RMP (up to 91\%) and INH (up to 88\%). However, the PZA level seems better in plasma availability (Table 3). Studies varied considerably at the time of blood sampling. This ranged from single-point sampling; at 2hours post-dose, ${ }^{31,34,35}$ and 2.5 hours post-dose ${ }^{26}$ to 9-time sampling to construct 24 hours AUC. ${ }^{27}$ However, all studies used standard methods for quantification of plasma level of the drug. The pharmacokinetics characteristics and associated treatment outcomes of each drug are presented below.

\section{Rifampicin}

Among the twelve studies, eleven studies assessed RMP pharmacokinetics of which eight reported treatment 
Table 2 Characteristics of Included Studies

\begin{tabular}{|c|c|c|c|c|c|c|}
\hline Author & Country & $\begin{array}{l}\text { Mean (Median) Age of } \\
\text { Study Participant }\end{array}$ & Study Design & Sample Size & $\begin{array}{l}\text { Population } \\
\text { Characteristics }\end{array}$ & $\begin{array}{l}\text { Risk } \\
\text { of } \\
\text { Bias }\end{array}$ \\
\hline $\begin{array}{l}\text { Aarnoutse, } \\
(2017)^{30}\end{array}$ & Tanzania & 33.5 & $\begin{array}{l}\text { Randomized } \\
\text { Controlled } \\
\text { Trial }\end{array}$ & 150 & I5 HIV positive & Low \\
\hline Burhan $(2013)^{34}$ & Indonesia & 35 & $\begin{array}{l}\text { Prospective } \\
\text { cohort }\end{array}$ & 181 & $\begin{array}{l}44 \text { diabetic } \\
19 \text { HIV positive }\end{array}$ & Low \\
\hline $\begin{array}{l}\text { Pasipanodya } \\
(2013)^{25}\end{array}$ & South Africa & 36 & $\begin{array}{l}\text { Prospective } \\
\text { cohort }\end{array}$ & 142 & $\begin{array}{l}\text { I5 HIV positive } \\
98 \text { have prior } \\
\text { tuberculosis }\end{array}$ & Low \\
\hline Prahl $(2014)^{31}$ & Denmark & 42 & $\begin{array}{l}\text { Prospective } \\
\text { cohort }\end{array}$ & 32 & 2 HIV positive & Low \\
\hline $\begin{array}{l}\text { Requena-Méndez } \\
(2014)^{33}\end{array}$ & Peru & 29 & $\begin{array}{l}\text { Prospective } \\
\text { cohort }\end{array}$ & 107 & $\begin{array}{l}25 \text { Diabetic } \\
30 \text { HIV positive }\end{array}$ & Low \\
\hline $\begin{array}{l}\text { Rockwood } \\
(2017)^{29}\end{array}$ & South Africa & 33 & $\begin{array}{l}\text { Prospective } \\
\text { cohort }\end{array}$ & 100 & $\begin{array}{l}65 \text { HIV positive } \\
4 \text { diabetic }\end{array}$ & Low \\
\hline $\begin{array}{l}\text { Sekaggya-Wiltshire } \\
(2018)\end{array}$ & Uganda & 34 & $\begin{array}{l}\text { Prospective } \\
\text { cohort }\end{array}$ & 227 & All HIV positive & Low \\
\hline Svensson $(2018)^{27}$ & $\begin{array}{l}\text { Tanzania and } \\
\text { South Africa }\end{array}$ & 34 & $\begin{array}{l}\text { Prospective } \\
\text { cohort }\end{array}$ & 97 & $\begin{array}{l}2 \text { patients HIV } \\
\text { positive }\end{array}$ & Low \\
\hline $\begin{array}{l}\text { Vela' squez } \\
(2018)^{32}\end{array}$ & Peru & 25 & $\begin{array}{l}\text { Randomized } \\
\text { Controlled } \\
\text { Trial }\end{array}$ & $\begin{array}{l}180 \text { randomized to three } \\
\text { arms } 10,15 \text {, and } 20 \mathrm{mg} / \mathrm{kg}\end{array}$ & $\begin{array}{l}2 \text { patients HIV } \\
\text { positive }\end{array}$ & Low \\
\hline Gengiah $(2014)^{26}$ & South Africa & 33 & $\begin{array}{l}\text { Prospective } \\
\text { cohort }\end{array}$ & 57 & $\begin{array}{l}\text { All are HIV } \\
\text { positive }\end{array}$ & Low \\
\hline $\begin{array}{l}\text { Ramachandran } \\
(2017)^{35}\end{array}$ & India & 38 & $\begin{array}{l}\text { Prospective } \\
\text { cohort }\end{array}$ & 1912 & $\begin{array}{l}19 \text { HIV positive } \\
53 \text { diabetic }\end{array}$ & Low \\
\hline $\begin{array}{l}\text { Ramachandran } \\
(2020)^{36}\end{array}$ & India & 39.5 & $\begin{array}{l}\text { Prospective } \\
\text { cohort }\end{array}$ & 404 & $\begin{array}{l}27 \text { HIV infected } \\
\text { I I } 3 \text { Diabetics }\end{array}$ & Low \\
\hline
\end{tabular}

outcomes. $^{27,28,30-32,35,36}$ Ramachandran et al found that $91 \%$, of the patients, had suboptimal concentrations of RMP ( $8 \mathrm{~g} / \mathrm{mL})$. This study evaluated factors influencing tuberculosis treatment outcomes in adult patients treated with thrice-weekly regimens. Lower RMP concentration was among the factors responsible for poor treatment outcome. $^{35}$ However, the study assessed multi-factors and the treatment was not according to current WHO recommendation. Similar authors recently have shown that low RMP concentrations were associated with poor outcomes. $^{36}$ Sekaggya-Wiltshire et al demonstrated that patients with both low RMP and INH Cmax have a moderately increased risk of unfavorable treatment outcomes, including death, treatment failure, loss to followup, and default. ${ }^{28}$ This study had a large sample size, but all study participants were HIV positive and there was no evidence on the effect of HIV on treatment outcome. Pasipanodya et al, compared treatment outcome using culture conversion at two months and long term outcome at two years for RMP peak concentration above and below $6.6 \mathrm{mg} / \mathrm{L}$. Among the patients who have a peak concentration below $6.6 \mathrm{mg} / \mathrm{L}, 19 \%$ have culture-positive at two months while only $1 \%$ have a culture-positive for the patient group who have a peak concentration above 


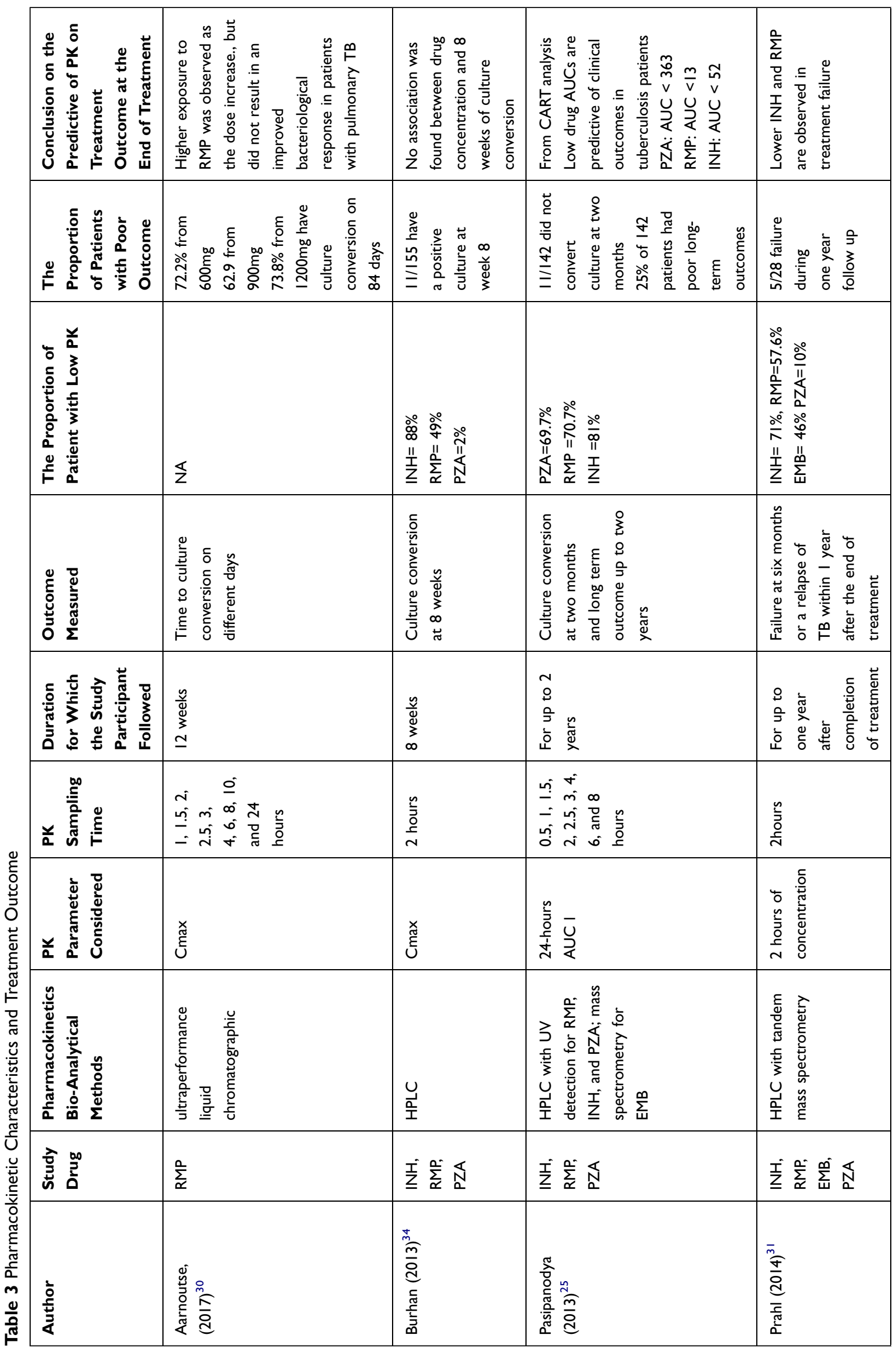




\begin{tabular}{|c|c|c|c|}
\hline 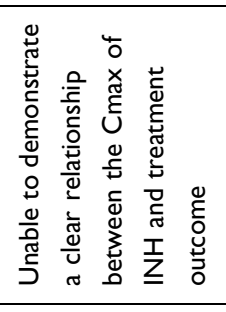 & 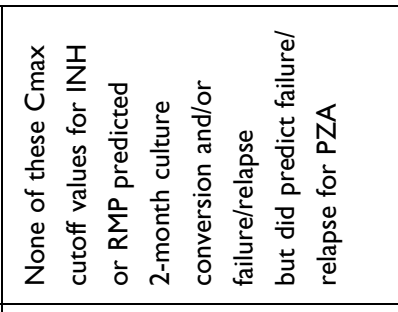 & 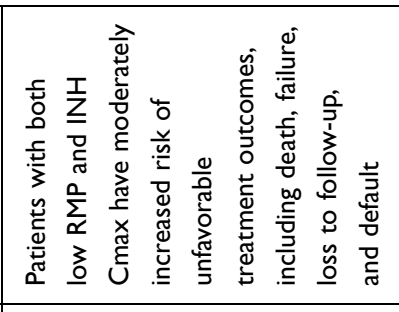 & 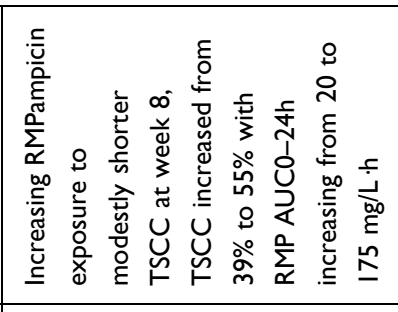 \\
\hline 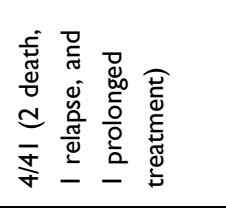 & 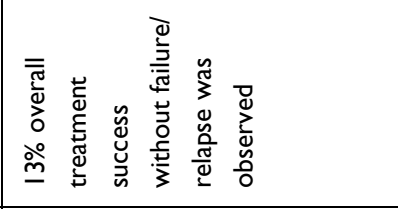 & 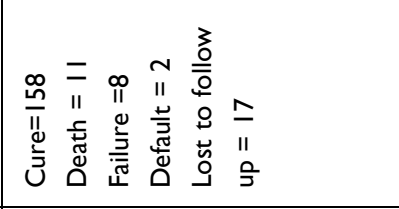 & $\mathbb{z}$ \\
\hline 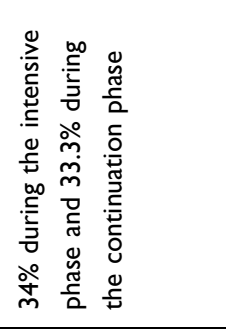 & 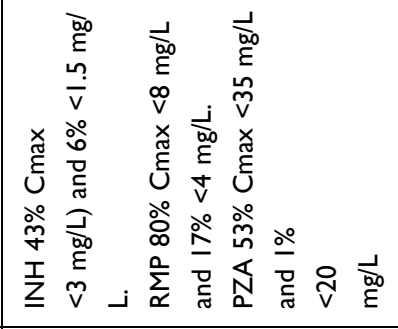 & 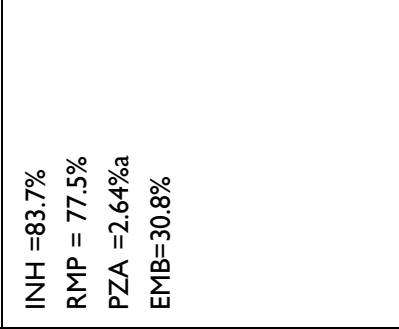 & $\S$ \\
\hline 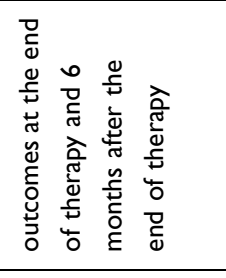 & 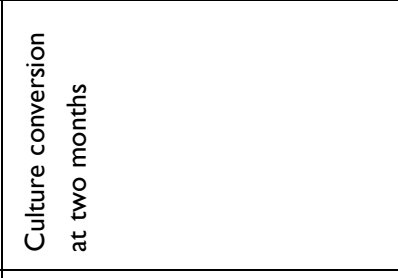 & 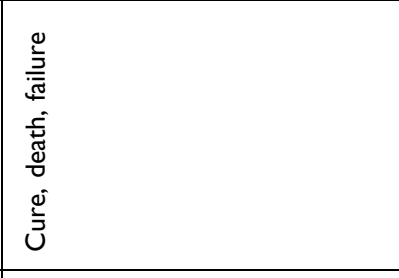 & 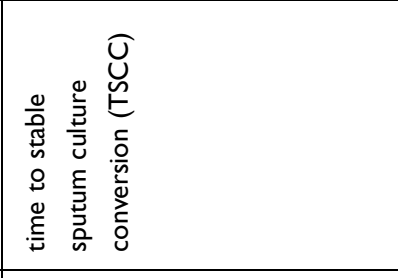 \\
\hline 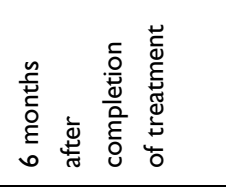 & 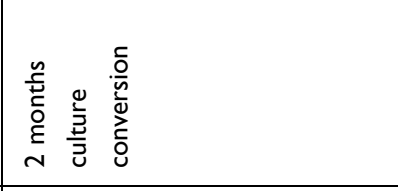 & 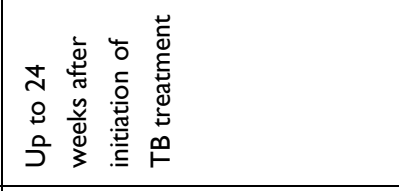 & 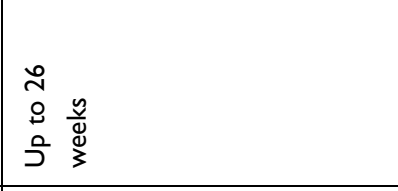 \\
\hline 雚 & 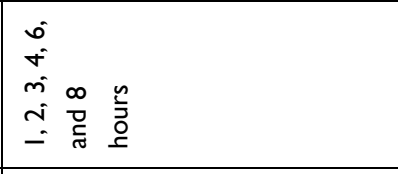 & 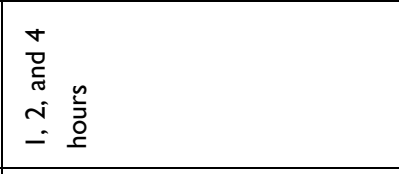 & 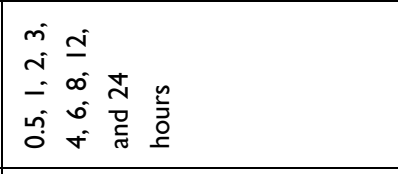 \\
\hline 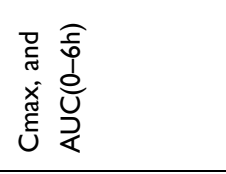 & 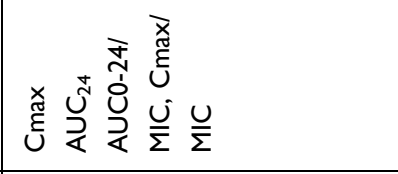 & 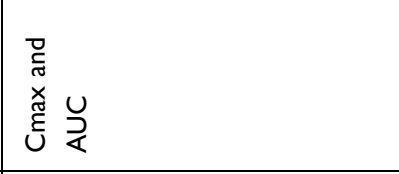 & 茯 \\
\hline 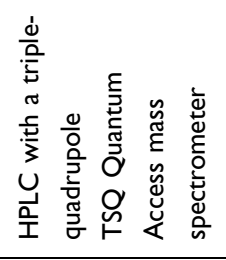 & 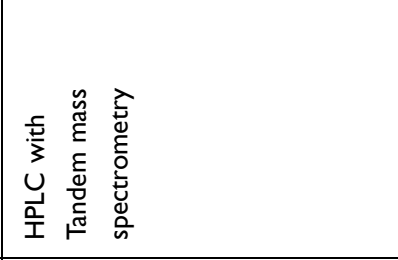 & 㟯 & 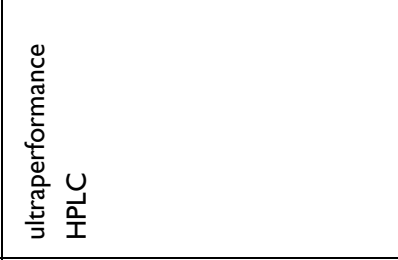 \\
\hline$\underline{\underline{\underline{I}}}$ & 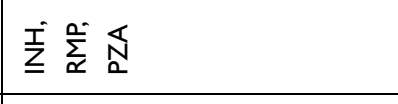 & 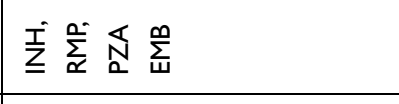 & $\sum_{\infty}^{0}$ \\
\hline 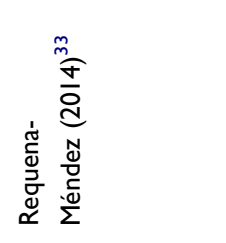 & 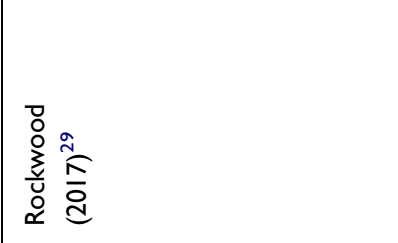 & 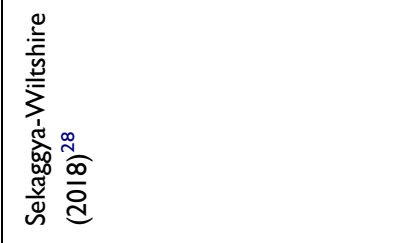 & 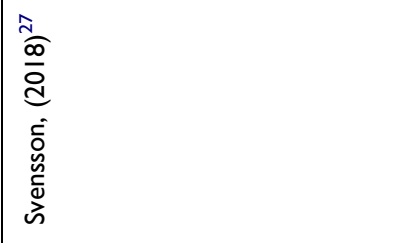 \\
\hline
\end{tabular}




\begin{tabular}{|c|c|c|c|c|}
\hline 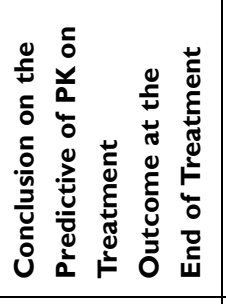 & 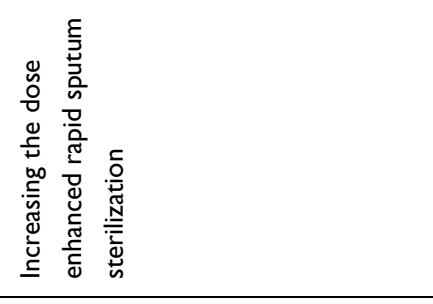 & 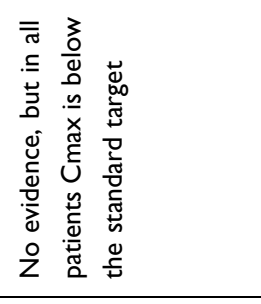 & 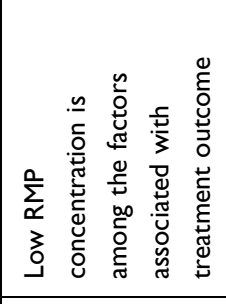 & 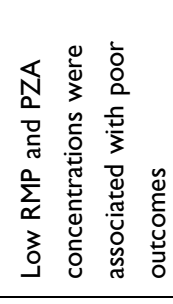 \\
\hline 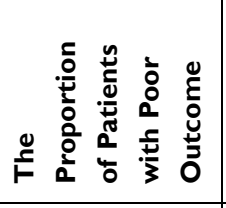 & 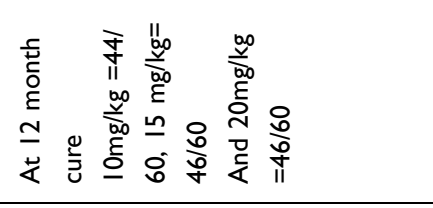 & 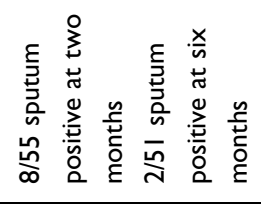 & 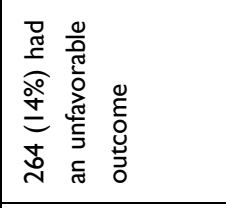 & 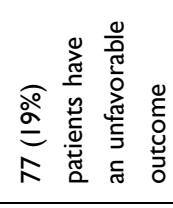 \\
\hline 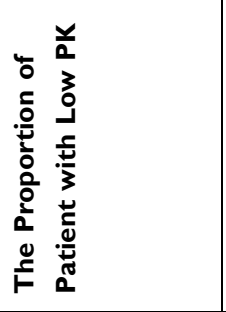 & $\frac{\pi}{z}$ & $\bar{q}$ & 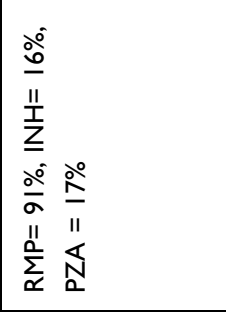 & $\mathbb{z}$ \\
\hline 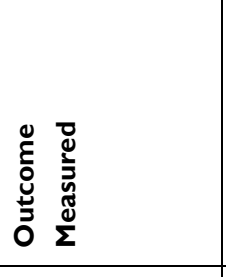 & 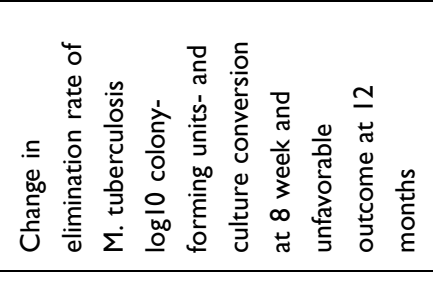 & 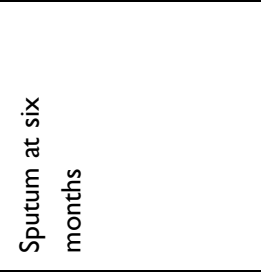 & 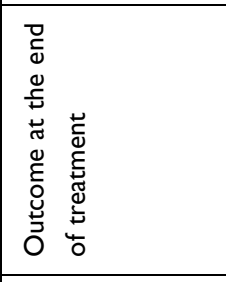 & 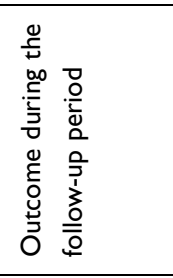 \\
\hline 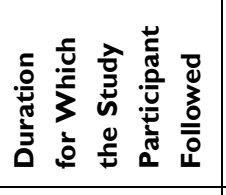 & 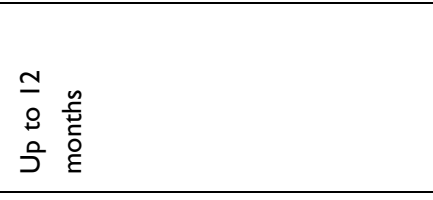 & 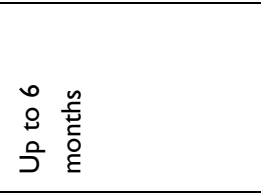 & 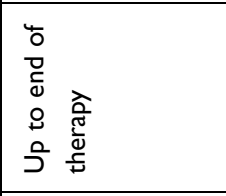 & 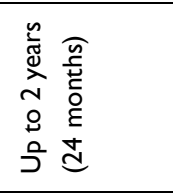 \\
\hline 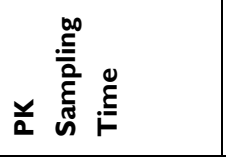 & $\underline{z}$ & 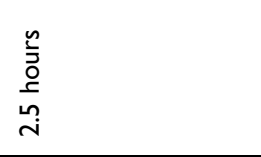 & $\frac{\stackrel{\underline{m}}{\bar{z}}}{\frac{0}{N}}$ & $\begin{array}{l}\frac{\underline{y}}{\bar{\nu}} \\
\frac{0}{N}\end{array}$ \\
\hline 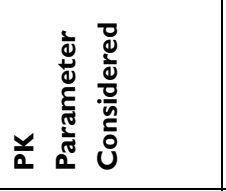 & 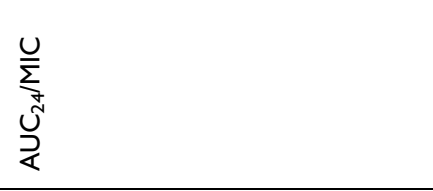 & 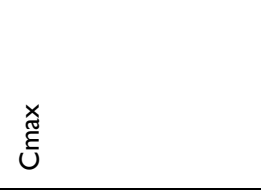 & 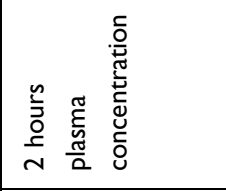 & 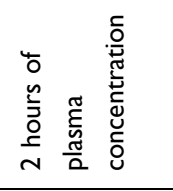 \\
\hline 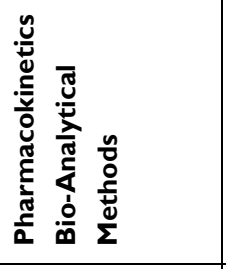 & $\frac{\pi}{z}$ & 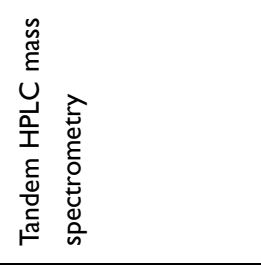 & 耑 & $\frac{U}{\vec{a}}$ \\
\hline 密哭 & $\sum_{\alpha}^{0}$ & $\sum_{\alpha}^{0}$ & 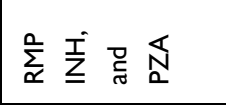 & 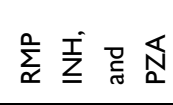 \\
\hline $\begin{array}{l}\frac{1}{0} \\
\frac{\dot{t}}{\alpha}\end{array}$ & 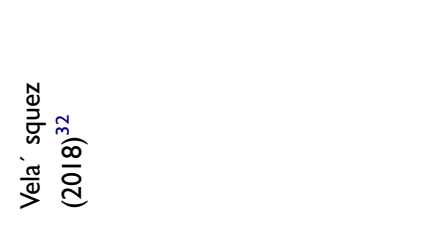 & 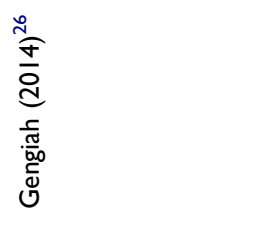 & 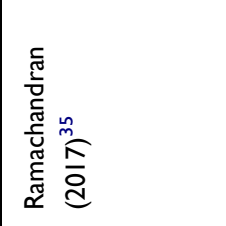 & 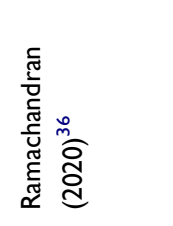 \\
\hline
\end{tabular}


$6.6 \mathrm{mg} / \mathrm{L}$. A similar difference was also observed for a long outcome for patient group dichotomized to above and below $13 \mathrm{mg} / \mathrm{L} \cdot \mathrm{h}$ AUC, $12 \%$ and $33 \%$ poor outcome respectively. ${ }^{25}$ Evidence on drug exposure and treatment outcome relationship was reported from two recent controlled clinical trials. ${ }^{30,32}$ In both studies increasing the dose of RMP increased drug exposure, however, improved faster culture conversion in the high exposure group was observed only in one study. ${ }^{32}$

Svensson et al found an association between RMP concentrations and time to stable sputum culture conversion. ${ }^{27}$ The proportion of patients with stable culture conversion on liquid medium at week 8 increased from $39 \%$ to $55 \%$, with the RMP AUC increased from 20 to $175 \mathrm{mg} / \mathrm{L} \cdot \mathrm{h}$. This study used only two dose levels, $10 \mathrm{mg} / \mathrm{kg}$ and $35 \mathrm{mg} / \mathrm{kg}$, and the safety of $35 \mathrm{mg} / \mathrm{kg}$ was not elucidated. Prahl et al found that treatment failure was observed at lower INH and RMP concentrations. ${ }^{31}$ The remaining three studies have not shown any evidence on the association of RMP concentration and treatment outcome. ${ }^{26,29,34}$

\section{Isoniazid}

The impact of plasma concentration of INH on treatment outcome was reported in eight studies. Requena-Méndez et al investigated the effects of dose, comorbidities, and food on INH pharmacokinetics in Peruvian tuberculosis patients. Although $34 \%$ of patients during the intensive phase and $33.3 \%$ during the continuation phase had lower INH concentration, no association between plasma concentration and treatment outcome was observed at the end of therapy. ${ }^{33}$ Burhan et al evaluated the association of 2hour plasma concentration of INH and treatment outcome, however, no association was found. ${ }^{34}$ Similarly, Rockwood et al reported no association between two months of culture conversion and pharmacokinetics. On the other hand, in Prahl's study, patients with treatment failure had a significantly lower 2hour plasma concentration of INH than those who were cured. ${ }^{31}$ Pasipanodya et al, compared treatment outcomes using culture conversion at two months for INH peak concentration above and below $8.8 \mathrm{mg} / \mathrm{L}$. Among the patients who have a peak concentration below $8.8 \mathrm{mg} / \mathrm{L}, 13 \%$ have culture-positive at two months while no patients have a culture-positive for the patient group who have a peak concentration above $8.8 \mathrm{mg} / \mathrm{L}$. For the long-term treatment outcome assessment, the patient group who have AUC of INH above and below $52 \mathrm{mg} / \mathrm{L} \cdot \mathrm{h}$ have $20 \%$ and $70 \%$ poor treatment outcomes respectively. ${ }^{25}$ Furthermore, Sekaggya-Wiltshire et al reported an association of low INH and RMP concentration with poor culture conversion. ${ }^{28}$

\section{Pyrazinamide}

The clinical impact of PZA drug concentrations was assessed in seven studies. However, only three studies reported the association between PZA plasma concentration and treatment outcome. ${ }^{25,34,36}$ Pasipanodya et al reported an association of AUC less than $363 \mathrm{mg} \cdot \mathrm{h} / \mathrm{L}$ with poor long-term outcomes. Moreover, the highest predictor of 2-month sputum conversion among all clinical factors examined was PZA peak concentration. Burhan et al evaluated the relationship between the plasma concentration of INH, RMP, and PZA and treatment outcome. No association was found between RMP and INH plasma concentration and treatment outcome. ${ }^{34}$ However, low pyrazinamide drug concentrations may be associated with a less favorable bacteriological response. Similarly, Rockwood et al found no association between Cmax of PZA and 2-month culture conversion culture but did predict failure or relapse. ${ }^{29}$ Another recent study reported that a $1-\mu \mathrm{g} / \mathrm{mL}$ decrease in pyrazinamide concentrations was associated with recurrence. ${ }^{36}$

\section{Discussion}

The WHO End TB Strategy has set an ambitious target to reduce TB deaths by $90 \%$ and to cut new cases by $80 \%$ between 2015 and 2030. ${ }^{2}$ To achieve these ambitious targets requires various interventions. First, achieving the WHO end TB targets will necessitate better, and early detection of TB which could halt TB transmission and hasten the decline in TB incidence and mortality, ${ }^{37,38}$ Second, we need safer, shorter, and more efficacious treatment for all forms of TB. Third, a vaccine would be the ultimate solution if found to be highly effective, safe, able to prevent pre-exposure, infection as well as reactivation. ${ }^{39,40}$ Since the existing anti-tubercular regimens made before the current advance in pharmacokinetic-pharmacodynamic (PK-PD), we are lacking evidence of exposure-response relationships even in today's tuberculosis pharmacotherapy. ${ }^{41}$ Owing to this gap WHO developed a technical report on the PK and PD of drugs used for tuberculosis treatment. ${ }^{13}$ This review examined the literature published over the last ten years reporting pharmacokinetics in particular plasma concentration of first-line anti-tubercular drug association with treatment outcome. 
The pharmacokinetics properties of first-line anti-TB drugs at which treatment success achieved have been published previously. ${ }^{16}$ The most common PK-PD measures used to describe anti-TB activities are the ratio of the Cmax relative to the MIC and the ratio of the area under the concentration-time curve at the end of the dosing interval relative to the MIC (AUC0 - 24/MIC). ${ }^{4}$ However, in several PK-PD studies, AUC0 - 24 or/and Cmax of the first-line drug was used as a measure of exposure and response. Similarly, nine of the eleven studies reported in this review used either Cmax, AUC, or both. Only one study described AUC24/MIC ${ }^{32}$ and one another both AUC24/MIC and Cmax/MIC. ${ }^{29}$ Besides, there is a variation in methods of determination of $\mathrm{Cmax}$ and AUC. For instance, Prahl et $\mathrm{al}^{31}$ measured the Cmax at 2hours post-dose, but Gengiah et al measured it at $21 / 2$ hours post-dose. ${ }^{22}$ For accurate prediction of AUC, although recent studies recommending a spare sample of plasma are emerging, ${ }^{42}$ intensive blood sampling is essential. But estimation of AUC is also done using different approaches.

The prevalence of low concentration in all studies is high. Previous systematic review and meta-analysis have also shown a high prevalence of low plasma concentration. ${ }^{20-22}$ However, they failed to find a strong association between low concentration and treatment outcomes. The type of studies included, the reliability of the current therapeutic range and variation on the report of treatment outcome were listed as factors responsible for lack of association. Owing to this the present review assessed only prospective and controlled clinical trials.

Only eight of the eleven studies have found the association between drug concentration and treatment outcome for RMP. ${ }^{25,27,28,30,32,35,36}$ Aarnoutse et al observed faster culture conversion in the higher RMPexposure group; ${ }^{30}$ Pasipanodya et al demonstrated AUCs of PZA, RMP and INH are predictive of clinical outcomes in tuberculosis patients; ${ }^{25}$ Prahl et al observed lower INH and RMP concentration in treatment failure, ${ }^{31}$ Sekaggya-Wiltshire et al reported patients with both low RMP and INH Cmax have delayed culture conversion; ${ }^{28}$ Svensson et $\mathrm{al}^{27}$ and Vela' squez et $\mathrm{al}^{32}$ have shown increasing RMP exposure to modestly shorter time to stable sputum culture conversion, and Ramachandran reported low RMP concentration as a predictive of treatment outcome. ${ }^{35}$ Similarly, a recent report of Ramachandran et al identified lower peak concentration or AUC as a predictor of culture conversion at two months and long-term treatment outcome respectively.
From these findings, one could best describe that increase in exposure to RMP increases anti-mycobacterial effects. However, using the current reference range it is difficult to dichotomize tuberculosis patients into non-respondents and respondents to anti-mycobacterial drug therapy based on the concentration.

The prevalence of low drug concentration is high for INH and PZA. The previous meta-analysis has shown that pharmacokinetics variability of INH mediates acquired drug resistance. ${ }^{43}$ Similarly, four studies reported the lower INH drug concentration associated with unfavorable treatment outcomes. ${ }^{25,28,31,33}$ Of the seven studies that assessed PZA concentration and treatment outcome Burhan et al and Pasipanodya et al identified low PZA concentration as a primary cause of unfavorable outcome. ${ }^{25,34}$ The results are consistent with the recent meta-analysis that needs attention in tuberculosis care. ${ }^{44}$

From this qualitative review, it is clear that increased exposure to drugs can improve the treatment outcome. However, further studies are required to validate this observation because of the following reasons. First, some patients are respondents to low and very low concentrations of the drug. ${ }^{26}$ Second, in most studies, the participants have a comorbid condition that could affect the outcome. Thus, to establish exposure-response relationship studies controlling confounding factors are important. Third, data are emerging on the effect of the strain of Mycobacterium tuberculosis variation on the clinical outcome [46] and variation on the critical concentration inhibiting wild-type Mycobacterium tuberculosis [47]. Therefore, to integrate the concentration of drug measurement into tuberculosis care and treatment better characterization of Cmax, AUC, Cmax/MIC, and/or AUC/MIC are needed.

\section{Conclusion}

This systematic review attempts to link drug exposure and treatment outcome. Although a limited number of prospective observational studies and controlled clinical trials are available for the review, RMP, PZA, and INH concentration have shown a link with treatment outcomes. An increase in exposure to RMP improved the outcome. A lower concentration of $\mathrm{NH}$ and PZA is observed in unfavorable treatment outcomes. On the other hand, a better outcome was observed in patients who have low exposure to these drugs. Further studies addressing the validity of the current reference range, plausible pharmacokinetics parameter, bacterial, and host factors are, 
however, are needed to predict drug concentration and treatment outcome association.

\section{Funding}

A study reported in this publication was supported by the Fogarty International Center and National Institute of Allergy and Infectious Diseases of the National Institutes of Health under Award Number D43 TW009127 and by the Center for Innovative Drug Development and Therapeutic Trials for Africa (CDT-Africa), Addis Ababa Univesity. The content is solely the responsibility of the authors and does not necessarily represent the official views of the National Institutes of Health or CDT-Africa, Addis Ababa University.

\section{Disclosure}

The authors report no conflicts of interest for this work.

\section{References}

1. WHO. Global Tuberculosis Report; 2019.

2. WHO. End TB Strategy; 2015.

3. Verbeeck RK, Günther G, Kibuule D, et al. Optimizing treatment outcome of first-line anti-tuberculosis drugs: the role of therapeutic drug monitoring. Eur J Clin Pharmacol. 2016;72(8):905-916. doi:10.1007/s00228-016-2083-4

4. Reynolds J, Heysell SK. Understanding pharmacokinetics to improve tuberculosis treatment outcome. Expert Opin Drug Metab Toxicol. 2014;10(6):813-823. doi:10.1517/17425255.2014.895813

5. Chideya S, Winston C, Peloquin C, et al. Isoniazid, rifampin, ethambutol, and pyrazinamide pharmacokinetics and treatment outcomes among a predominantly HIV-infected cohort of adults with tuberculosis from Botswana. Clin Infect Dis. 2009;48(12):1685-1694. doi: $10.1086 / 599040$

6. Chang J-T, Dou H-Y, Yen C-L, et al. Effect of Type 2 diabetes mellitus on the clinical severity and treatment outcome in patients with pulmonary tuberculosis: a potential role in the emergence of multidrug-resistance. Formosan Med Assoc. 2011;110(6):372-381. doi:10.1016/S0929-6646(11)60055-7

7. Dooley KE, Lahlou O, Ghali I, et al. Risk factors for tuberculosis treatment failure, default, or relapse and outcomes of retreatment in Morocco. BMC Public Health. 2011;11(1):140. doi:10.1186/14712458-11-140

8. Musaazi J, Sekaggya-Wiltshire C, Kiragga AN, et al. Sustained positive impact on tuberculosis treatment outcomes of TB-HIV integrated care in Uganda. Int J Tuberc Lung Dis. 2019;23(4):514-521. doi:10.5588/ijtld.18.0306

9. Huang D, Wang Y, Wang Y, et al. The impact of diabetes mellitus on drug resistance in patients with newly diagnosed tuberculosis: a systematic review and meta-analysis. Ann Palliat Med. 2020;9 (2):152-162. doi:10.21037/apm.2020.02.16

10. Bhargava AB. M. Tuberculosis deaths are predictable and preventable: comprehensive assessment and clinical care is the key. J. Clin. Tuberc. Other Mycobact. Dis. 2020;19,(100155):(2020).

11. Ramesh Jayaram RKS, Gaonkar S, Parvinder Kaur BL, et al. Isoniazid Pharmacokinetics-Pharmacodynamics in an Aerosol Infection Model of Tuberculosis. Antimicrobial Agents Chemother. 2004;48(8):2951-2957.
12. Jotam G, Pasipanodya EN, Romero K, Hanna D, Gumbo T. Systematic Analysis of Hollow Fiber Model of Tuberculosis Experiments. Clin Infect Dis. 2015;61.

13. WHO. Technical Report on the Pharmacokinetics and Pharmacodynamics (PK/PD) of Medicines Used in the Treatment of Drug-Resistant Tuberculosis; 2018.

14. Ishimoto T, Kato Y. [Physiolgically-based pharmacokinetics: theory and examples.]. Clin Calcium. 2016;26(11):1529-1537. Japanese.

15. Davies PD. The role of DOTS in tuberculosis treatment and control. Am J Respir Med. 2003;2(3):203-209. doi:10.1007/BF03256649

16. Alsultan A, Peloquin CA. Therapeutic drug monitoring in the treatment of tuberculosis: an update. Drugs. 2014;74(8):839-854. doi:10.1007/s40265-014-0222-8

17. Hall RG, Leff RD, Gumbo T. Treatment of active pulmonary tuberculosis in adults: current standards and recent advances. Insights from the Society of Infectious Diseases Pharmacists. Pharmacotherapy. 2009;29(12):1468-1481. doi:10.1592/phco.29.12.1468

18. Jotam G, Pasipanodya SS, Gumbo T. Meta-analysis of clinical studies supports the pharmacokinetic variability hypothesis for acquired drug resistance and failure of antituberculosis therapy. Clinical Infectious Diseases. 2012;55(2):169-177. doi:10.1093/cid/cis353

19. Wilby KJ. Review of evidence for measuring drug concentrations of first-line antitubercular agents in adults. Clin Pharmacokinet. 2014;53:873-890.

20. Mota L, Campbell JR, Cook VJ, Marra F, Johnston J. Therapeutic drug monitoring in anti-tuberculosis treatment: a systematic review and meta-analysis. Int J Tuberc Lung Dis. 2016;20(6):819-826.

21. Sekaggya-Wiltshirea C, Mohammed Lamordea AN, Kiraggaa KE, et al. The utility of pharmacokinetic studies for the evaluation of exposureresponse relationships for standard dose anti-tuberculosis drugs. Tuberculosis. 2018;108:77-82.

22. Perumal R, Naidoo K, Naidoo A, et al. A systematic review and meta-analysis of first-line tuberculosis drug concentrations and treatment outcomes. Int J Tuberc Lung Dis. 2020;24(1):48-64.

23. Daly J, et al. A hierarchy of evidence for assessing qualitative health research. $J$ Clin Epidemiol. 2007;60(1):43-49. doi:10.1016/j. jclinepi.2006.03.014

24. Tesemma Sileshi ET, Makonnen E, Aklilu E. The influence of pharmacokinetics of first line anti-tubercular drugs on treatment outcome: a systematic review. PROSPERO. 2019.

25. Pasipanodya JG, McIlleron H, Burger A, et al. Serum drug concentrations predictive of pulmonary tuberculosis outcomes. $J$ Infect Dis. 2013;208(9):1464-1473. doi:10.1093/infdis/jit352

26. Gengiah TN, Botha JH, Soowamber D, et al. Low rifampicin concentrations in tuberculosis patients with HIV infection. $J$ Infect Dev Ctries. 2014;8(8):987-993. doi:10.3855/jidc.4696

27. Svensson EM, Svensson RJ, Te Brake LHM, et al. The potential for treatment shortening with higher rifampicin doses: relating drug exposure to treatment response in patients with pulmonary tuberculosis. Clin Infect Dis. 2018;67(1):34 41. doi:10.1093/cid/ciy026

28. Sekaggya-Wiltshire C, von Braun A, Lamorde M, et al. Delayed sputum culture conversion in tuberculosis-human immunodeficiency virus-coinfected patients with low isoniazid and rifampicin concentrations. Clin Infect Dis. 2018;67(5):708-716. doi:10.1093/ cid/ciy179

29. Rockwood N, Pasipanodya JG, Denti P, et al. Concentration-dependent antagonism and culture conversion in pulmonary tuberculosis. Clin Infect Dis. 2017;64(10):1350-1359. doi:10.1093/cid/cix158

30. Aarnoutse RE, et al. Pharmacokinetics, tolerability, and bacteriological response of rifampin administered at 600, 900, and 1200 milligrams daily in patients with pulmonary tuberculosis. Antimicrob Agents Chemother. 2017;61(11).

31. Prahl JB, Johansen IS, Cohen AS, et al. Clinical significance of 2 $\mathrm{h}$ plasma concentrations of first-line anti-tuberculosis drugs: a prospective observational study. J Antimicrob Chemother. 2014;69 (10):2841-2847. doi:10.1093/jac/dku210 
32. Velasquez GE, Brooks MB, Coit JM, et al. Efficacy and safety of high-dose rifampin in pulmonary tuberculosis. a randomized controlled trial. Am J Respir Crit Care Med. 2018;198(5):657-666. doi:10.1164/rccm.201712-2524OC

33. Requena-Mendez A, Davies G, Waterhouse D, et al. Effects of dosage, comorbidities, and food on isoniazid pharmacokinetics in Peruvian tuberculosis patients. Antimicrob Agents Chemother. 2014;58(12):7164-7170. doi:10.1128/AAC.03258-14

34. Burhan E, Ruesen C, Ruslami R, et al. Isoniazid, rifampin, and pyrazinamide plasma concentrations in relation to treatment response in Indonesian pulmonary tuberculosis patients. Antimicrob Agents Chemother. 2013;57(8):3614-3619. doi:10.1128/AAC.02468-12

35. Ramachandran G, et al. Factors influencing tuberculosis treatment outcome in adult patients treated with thrice-weekly regimens in India. Antimicrob Agents Chemother. 2017;61(5).

36. Geetha Ramachandran PC, Gaikwad S, Kupparam HKA, et al. Subtherapeutic rifampicin concentration is associated with unfavorable tuberculosis treatment outcomes. Clin Infect Dis. 2020;70 (7):1463-1470. doi:10.1093/cid/ciz380

37. Keeler E, Perkins MD, Small P, et al. Reducing the global burden of tuberculosis: the contribution of improved diagnostics. Nature. 2006;444(S1):49-57. doi:10.1038/nature05446

38. Walzl G, McNerney R, Du Plessis N, et al. Tuberculosis: advances and challenges in development of new diagnostics and biomarkers. Lancet Infect Dis. 2018;18(7):e199-e210. doi:10.1016/S14733099(18)30111-7
39. Lienhardt $\mathrm{C}$, Raviglione $\mathrm{MC}$. TB elimination requires discovery and development of transformational agents. Appl Sci. 2020;10(7).

40. Floyd K, Glaziou P, Houben RMGJ, et al. Global tuberculosis targets and milestones set for 2016-2035: definition and rationale. Int J Tuberc Lung Dis. 2018;22(7):723-730. doi:10.5588/ijtld.17. 0835

41. McCallum AD, Sloan DJ. The importance of clinical pharmacokinetic-pharmacodynamic studies in unraveling the determinants of early and late tuberculosis outcomes. Int $J$ Pharmacokinetics. 2017;2(3):195-212. doi:10.4155/ipk-2017-0004

42. Saktiawati AMI, Harkema M, Setyawan A, et al. Optimal sampling strategies for therapeutic drug monitoring of first-line tuberculosis drugs in patients with tuberculosis. Clin Pharmacokinet. 2019;58 (11):1445-1454. doi:10.1007/s40262-019-00763-3

43. Nicol MP, Wilkinson RJ. The clinical consequences of strain diversity in Mycobacterium tuberculosis. Trans $R$ Soc Trop Med Hyg. 2008;102(10):955-965. doi:10.1016/j.trstmh.2008.03.025

44. Dusthackeer A, Saadhali SA, Thangam M, et al. Wild-Type MIC distribution for re-evaluating the critical concentration of anti-tb drugs and pharmacodynamics among tuberculosis patients from South India. Front Microbiol. 2020;11:1182. doi:10.3389/ fmicb.2020.01182

\section{Publish your work in this journal}

Clinical Pharmacology: Advances and Applications is an international, peer-reviewed, open access journal publishing original research, reports, reviews and commentaries on all areas of drug experience in humans. The manuscript management system is completely online and includes a very quick and fair peer-review system, which is all easy to use. Visit http://www.dovepress.com/testimonials.php to read real quotes from published authors. 